\title{
Modelling stakeholder satisfaction for conflict resolution in wildlife management: a case of wolf population in Sweden
}

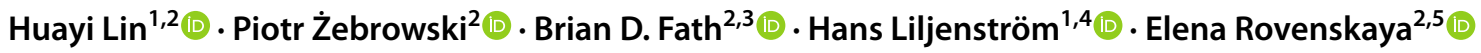

Received: 15 January 2020 / Revised: 1 April 2021 / Accepted: 4 May 2021 / Published online: 4 June 2021

(c) The Author(s) 2021

\begin{abstract}
The Swedish wolf population has rebounded from near extinction in the 1960s to around 365 individuals in 2020, after the implementation of the Hunting Act (jaktlagen) in 1966. This recent increase in the wolf population has evoked a serious divide between "pro-wolf" and "anti-wolf" Swedish citizens. Despite the continuous efforts by the Swedish government to reconcile this antagonism, the conflicts are persistent with a sign of impasse. In this paper, we present a modelling tool, which can bring transparent and "structured dialogue to the opposing positions." This approach includes a stylized framework for quantitative modelling of stakeholders' satisfaction levels regarding their preferred size of the wildlife population in question, based on the concept of satisfaction functions. We argue that this framework may contribute to conflict resolution by bringing a common understanding among stakeholders, facilitate a societal discourse, and potentially help to assess likely support for conservation policies. We present a showcase application of this modeling tool in the context of the conflict over the Swedish wolf conservation policies. The model is informed using a thorough literature review as well as interviews, which identified relevant stakeholder groups and respective drivers of their attitudes towards wolves.
\end{abstract}

Keywords Conflict resolution · Conservation · Modelling · Population biology $\cdot$ Satisfaction levels $\cdot$ Wolves $\cdot$ Stakeholders . Wildlife management

\section{Introduction}

Huayi Lin

huayi.lin@slu.se

Piotr Żebrowski

zebrowsk@iiasa.ac.at

Brian D. Fath

bfath@towson.edu

Hans Liljenström

hans.liljenstrom@slu.se

Elena Rovenskaya

rovenska@iiasa.ac.at

Dept of Energy and Technology, SLU, Uppsala, Sweden

2 Advancing Systems Analysis Program, IIASA, Laxenburg, Austria

3 Department of Biological Sciences, Towson University, Towson, USA

4 Agora for Biosystems, Sigtuna, Sweden

5 Faculty of Computational Mathematics and Cybernetics, Lomonosov Moscow State University, Moscow, Russian Federation
The Swedish wolf population has gone through a significant change in history as people's attitudes towards them have fluctuated. About 180 years ago, the wolf population in Sweden was estimated to be approximately 1,500 individuals (Sjölander-Lindqvist 2011). Due to encouragement by the government on hunting wolves over the years, by the 1960s, wolves almost went extinct (Ericsson and Heberlein 2003) and only three individuals were reported in that period (Liberg 2006.). At that time, the Swedish government started its wildlife conservation efforts regarding wolves and other large predators, and implemented the Hunting Act ( $\mathrm{Sw}$. jaktlagen) in 1966. Since then, wolves have been protected in Sweden and their population has gradually recovered to the current (estimated) level of about 365 individuals (Naturvårdsverket 2020).

During the last four decades, the reappearance of wolves has induced a series of social problems and contentious debates within the Swedish society (Ericsson and Heberlein 2003; Ednarsson 2006; Karlsson and Sjöström 2007; Eriksson 2013; Stohr and Coimbra 2013; Rogers 2014; Nilsson et al. 2020; Skogen and Krange 2020). These debates focus mainly on the 
impact of wolves on people's lives, primarily hunting and sheep and goat farming, and the necessity and legitimacy of wolf reestablishment. Historical records indicate that, in the past, Swedish hunters were more positive towards wolf reestablishment than today (Andersson et al. 1977). As the wolf population grew, hunters gradually became the most negative towards them (Dressel et al. 2015; Ericsson and Heberlein 2003; Røskaft et al. 2003). Other objectors such as livestock owners and reindeer herders also claim that wolves negatively affect their lives. Advocates of wolf conservation, on the contrary, consider the wolf population as too small due to inbreeding, illegal hunting, and other ecological factors (Eriksson 2017a, b; Nilsson et al. 2020; Sjölander-Lindqvist 2008). They strongly oppose any action that encroaches on the existence and welfare of wolves. Until now, every target size of the wolf population proposed by the Swedish government has raised severe resistance in society by both advocates and objectors.

In 2009, the Swedish Government approved licensed hunting of 27 wolves in early 2010 (Arnbom 2011) in order to eliminate some individuals with primarily biological defects and spare some "population space" for the "new blood" (to satisfy the advocates who were concerned with the inbreeding problem in the wolf population) and to curb wolf population growth (to satisfy the objectors). This decision triggered an outburst of debate on wolf management in the society and polarized the country into two camps (Eriksson 2016). Still, licensed hunting has continued over the past years.

\section{Controversies around impacts of wolves}

The presence of wild wolves in Sweden has both positive and negative impacts from environmental, economic, and social perspectives. Environmentally, as top predators, wolves are regarded as an important part of a healthy ecosystem with a rich biodiversity (Sjölander-Lindqvist 2008). In their absence, the population of other species, such as deer and moose, would expand uncontrolled, which then may have cascading effects on the ecosystem to various degrees (Kuijper et al. 2016). Swedish environmentalists in general are advocates for wolves due to this reason (Sjölander-Lindqvist 2009). Most urbanites are either neutral or positive towards wolves, for similar reason as environmentalists. However, many objectors doubt the necessity and the importance of the ecological role of wolves (Ericsson and Heberlein 2003; Ericsson et al. 2008; Sjölander-Lindqvist 2008; Dressel et al. 2015; Eriksson et al. 2015). In addition, some people argue that the function of the wolf as a big predator is substituted by the hunter and the Swedish landscape is mostly formed by secondary forest, which is governed and managed by humans. Wolves had an important role to play in ecosystems of pristine forests, the argument goes, but are no longer needed in the "artificial" nature of Sweden. Even though this view is questioned by many, it is still deeply rooted in the mentality of many objectors and drives their emotions, rationality, and actions. In addition to the discussion on the role of wolves, another ongoing debate focuses on the question of a desired size of wolf population. Although some experts have suggested certain numbers (Bruford 2015; Sjögren-Gulve and HörnellWillebrand 2015), there is still a lack of consensus. During the past decades, the government has changed the target population size several times, heating the dispute and engendering more distrust between citizens and the government.

Economically, wolves prey on or otherwise attack livestock and reindeer, causing losses to the livestock owners (Creel and Christianson 2007; Muhly et al. 2010) and reindeer herders. Livestock owners usually receive compensation for lost animals as well as for undertaking preventative measures against wolves, such as electric fences (Bostedt and Grahn 2008). However, some livestock owners claim that the compensation is not high enough to cover their losses because the latent value of the attacked livestock is ignored. On the other hand, wolf advocates think that the compensation is often higher than the real losses. Reindeer herders, as a special minority in the society, are authorized to kill wolves hunting on their land. They also receive compensation for reindeer losses.

Wolves compete with hunters for prey on both small and large wild animals, including deer and moose. Occasionally, they also hurt and kill hunting dogs, causing economic and emotional losses to hunters (Ericsson and Heberlein 2003; Skogen and Krange 2020; Treves et al. 2013; Williams et al. 2002). There is no compensation to the loss of the prey for the hunters, but they receive compensation for the loss of hunting dogs. Besides the direct costs caused by wolves, the tax revenues used to finance various protection measures against the wolves are considered as disproportional compared to the other more demanding and important matters for the society. On the other hand, wolves may generate economic revenue as an attraction for ecotourism (Gössling and Hultman 2006).

Socially, wolf advocates take wolves as a symbol of nature and animal rights (Castle 2015; Price 2013). Interest and concern for all nature, including wolves, could be seen as an expression of biophilia (Wilson 1984; Kellert and Wilson 1993), which postulates that humans have an affinity toward nature and all forms of life. Access to and interaction with nature is seen as important to be preserved for future generations, and wolves are considered an attractive part of this nature by many advocates. On the other hand, some objectors think that wolves are vicious and ravenous animals. Hunters, livestock owners, and reindeer herders argue that their traditional activities, including recreation, lifestyle, social bond, and identity, have been harmed by wolves, and hence, the entire rural culture is being threatened (SjölanderLindqvist 2011; von Essen and Tickle 2020), which is a view that many wolf advocates argue against. There is also an issue on conflict between the city and the countryside or the 
center and the periphery. People in the countryside argue that the conservation policies are made by people living in cities or in the capital (Stockholm) who are unaware of the suffering of people living in the countryside. People living in cities may think people living in the countryside are selfish and undereducated by not realizing the importance of wolf conservation. Besides the economic losses, wolves are also treated as a symbol for people to express the impasse of conflict resolution in the long-standing divide between the city and the countryside (Eriksson 2017a, b; Sjölander-Lindqvist et al. 2015; Skogen et al. 2017; Skogen and Krange 2020; von Essen and Allen 2015; von Essen et al. 2015).

The conflicts around wolf conservation are partly rational and partly emotional. In most forms of meeting with stakeholders from different perspectives, no matter from which side, emotional debates always upgrade the conflict and distort efforts at consensus building and peace-making (Eriksson 2017a, b; Matti and Sandström 2011, 2013; Nilsson et al. 2020; Eriksson et al. 2015; Skogen and Krange 2020).

\section{Policies on wolf conservation and societal response}

To promote conservation and public acceptance, the Swedish government has implemented a series of measures, such as forming a Council for Predator Issues to help the Swedish Environmental Protection Agency (SEPA) to organize various local mobilization programs, establishment of Regional Predator Groups (RPG), compensation for losses due to wolf attacks, compensation for preventative measures (such as electric fences), decentralization of the wolf management to county level, etc. However, the polarization of society over the wolf issue continues (Berg and Solevid 2015; SjölanderLindqvist 2008) leading to highly emotional disputes, with sides of the conflict making verbal threats against each other, and even to unlawful actions (such as poaching).

\section{Importance of the wolf population size in wolf management}

Although some scholars argue that the conflict around conservation is not about wolves per se (Sjölander-Lindqvist 2009), a specified wolf population is essential to the wolf management and an important cause of the attitudinal divide in the Swedish society (Eriksson 2013). As a conservation index, the size of the wolf population is used as a target by the government, and it is also widely publicized and discussed in media and by stakeholders from all strata in the society. The population size can be accompanied by other indices, such as geographical distribution, inbreeding degree, and the relevant policies, but the population size is always a clear visual index to judge the wolf conservation status and to implement policies. Almost every year, when the wolf population size is published by the SEPA, it ignites new debates in media and elsewhere. In our interviews with leaders from hunter organizations, they acknowledged that they already agreed to have some population of wolves to exist in Sweden, but they also pointed out that the government changing the target number of the wolf population every now and then irritates them the most. Therefore, determining a broadly agreeable wolf population size would be essential for settling the debate.

\section{Studies on the conflict regarding wolf conservation in Sweden and other countries}

Previous studies concerning the Swedish wolf conservation conflict have recognized that the issue is entangled in a complex interlinkage of cultural, historical, and ethical aspects that decision makers have failed to address in their attempts to resolve it (Sjölander-Lindqvist 2008; Sjölander-Lindqvist and Cinque 2014; Sjölander-Lindqvist et al. 2015; Eriksson $2017 \mathrm{a}, \mathrm{b})$. A few studies have focused on communication and deliberation between stakeholders and decision makers and have suggested process and policy improvements (Røskaft et al. 2007; Dressel et al. 2015; Sjölander-Lindqvist et al. 2015; von Essen and Allen 2015; von Essen et al. 2015; von Essen 2016). Other studies have analyzed selected aspects of this multi-faceted problem: economic impacts of the wolves on local communities (Naughton-Treves et al. 2003; Nyhus et al. 2003; Treves et al. 2009), people's attitudes towards the wolf (Karlsson and Sjöström 2007; Heberlein and Ericsson 2008; Frank et al. 2015), and the ecological condition which the wolves need to survive and thrive within the natural and social limitation of rural areas of the modern age (SjögrenGulve and Hörnell-Willebrand 2015). However, none of these studies has taken into consideration all the abovementioned aspects together in a systematic and holistic manner.

Nie (2002) in the USA and Bisi et al. (2007) in Finland suggested that the wolf issue is a value-based political conflict that goes beyond science, biology, and techno-rational approaches. Human values and ethics at the center of the analysis (Nie 2002) and societal values ultimately determine the wolf recovery (Musiani and Paquet 2004). Maji ć and Bath (2010) pointed out in an attitude change study in Croatia that human dimensions' research can serve as an evaluative tool to help management to be more adaptive and effective. Sponarski et al. (2014) found in Canada that shared values translate to attitudes towards wolves, which in turn are predictors of and behavior support for successful conservation, while public trust in an agency is a mediator between shared values and attitudes. Glikman et al. (2012) and Jacobs et al. (2014) found that emotion is more effective than cognition on people's acceptance on lethal control on wolves in Italy, Netherlands, and Canada. Many of these studies mentioned that values and attitudes are essential to the conflict resolution. Yet, none of them intended to build 
a holistic picture that encompasses the wildlife population, concerned stakeholders, their values, divergent perspectives, and attitudes and presents the complicated problem at one glance. Brown and Decker (1979) and Decker and Purdy (1988) made an integrated system with different attitudes of farmers towards the density of white-tailed deer in New York and developed a wildlife acceptance capacity based on both biological carrying capacity and social carrying capacity to aid deer population management objectives. Nonetheless, further work remained to link the drivers and the farmers' attitudes.

\section{Drivers of the conflict and the interests concerned}

Conflict drivers can be primary or secondary. Primary drivers generate the underlying conflict from the beginning. For wolf supporters, primary drivers are concerns for ecosystem health, conservation and biodiversity, ecotourism, etc. (Eriksson 2017a, b; Nilsson et al. 2020; Sjölander-Lindqvist 2008). For wolf objectors, primary drivers are economic losses due to predation on livestock, reindeer, and hunting dogs (Ericsson and Heberlein 2003; Skogen and Krange 2020; Treves et al. 2013; Williams et al. 2002), disturbance on livelihood in the countryside including animal herding and hunting (Schroeder et al. 2018; Sjölander-Lindqvist 2011; von Essen and Tickle 2020; Young et al. 2015), etc. The primary drivers can be ascribed to different interests concerned by the stakeholders, which will be listed afterwards. The secondary drivers of the conflict are more structural, e.g., a government policy perceived as unfair between the city and the countryside (Ericsson et al. 2008), inefficient organization during the stakeholder meeting, and uncontrolled Internet debates that ferment antagonistic emotion. Comparing to primary drivers, secondary drivers are the catalyst of the conflict, not the cause. Thus, our study focuses on primary drivers, which link to the interests relating to the wolf reestablishment.

\section{Benefits of modeling the system as an integrated whole}

A successful wildlife management policy, clearly needed in context of the Swedish wolf population, requires a creative practice that is guided by diverse expertise and addresses often conflicting needs and customs of the stakeholders involved. It is convenient to recognize such a complex issue as a wicked problem (Head and Alford 2015; Mason et al. 2018). To tackle such problem, one needs to adopt a holistic perspective on the interactions between elements of the system at hand and build its integrated representation (Anderson et al., 2005; Cilliers 1998).

Peter and Swilling (2014) argue that addressing the conservation conflict with clashing interests of stakeholders requires an integrated modelling approach, which aims at including a broad spectrum of perspectives relevant to the problem at hand (Loorbach and Rotmans 2006). Building a multi-aspect model may bring a better structure to analyze the complex conflict of stakeholders over the wolf issue and help the decision makers to negotiate the multiple facets of this problem, which is essential to the conflict resolution (Nie 2002). Moreover, if the modelling process involves stakeholder interests, it has a potential to enhance participation and a sense of process ownership, provided that stakeholders feel that their perspectives are meaningfully represented and taken into consideration. Integrated modelling may facilitate "shared understanding," by exposing all sides in the conflict to the opponents' points of view (Voinov and Bousquet 2010; Wiek et al. 2012).

A modelling approach can also help to rationalize an emotion-charged dispute. Modelling can facilitate people with defined rationality and consistency in their thinking of the process, providing an explicit analysis rather than any implicit pondering inside one's mind (Pidd 2010). In the virtual worlds of simulations, decision makers can develop management skills, take experiments, and play out scenarios (Sterman 2001). By presenting the interests and concerns of both sides of the conflicts, models can help people be more sympathetic and focus on finding solution instead of defeating the rivals (Fig. 1).

\section{Aims and the structure of the paper}

In this paper, we consider a complex wicked problem of finding a societal compromise on wildlife population size, specifically wolves in Sweden. To clearly describe the conflict, we apply an integrated modeling approach based on satisfaction levels of opposing stakeholders and their relation

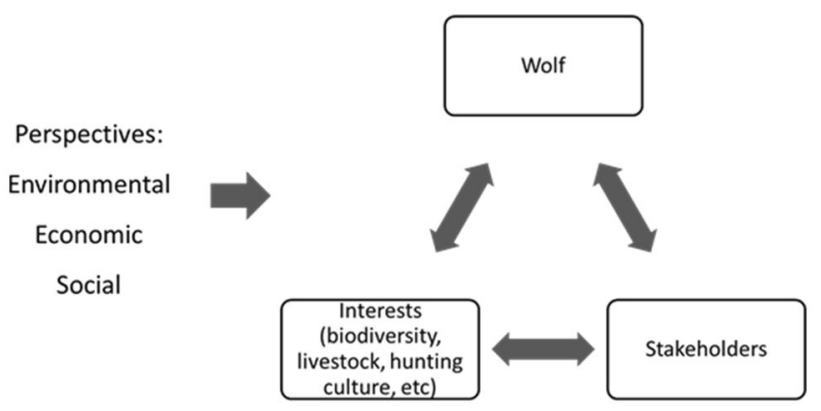

Fig. 1 Conceptual structure of problem of Swedish wolf management. Figure 1 is a showcase of a holistic system including the main primary factors of the issue, their relationship, and in what dimensions (perspectives) they are analyzed. Wolves add some interests of the stakeholders in terms of their biological and social values which bring ecological and cultural benefits. On the other hand, wolves damage some interests by predation on animals, causing economic and cultural losses to livestock owners, hunters, and reindeer owners 
to the wildlife population. This approach consists of two steps. First, we formulate satisfaction functions to represent the fulfillment of the drivers (satisfaction levels) in relation to the size of the wolf population. Next, we combine satisfaction functions of pro-wolf and anti-wolf stakeholders and semi-quantitatively assess the divergence of their satisfaction levels as a function of the wolf population size. In this way, we can measure the progress towards reaching consensus, as well as to identify the space for compromise (i.e., a wolf population size with which all sides are reasonably satisfied).

In "Framing the stakeholder landscape," the first of the aforementioned steps is carried out through an analysis of the different stakeholder groups and drivers of their satisfaction levels in relation to the size of the wolf population. We include some selected drivers regarding values and identity of stakeholders, which we consider to be of importance for our conceptual model.

In "Model of stakeholders' satisfaction," the second step involves constructing formal mathematical functions representing satisfaction levels of the stakeholders in relation to the size of the wolf population. Overall, this approach aims at providing a framework to synthesize the main drivers for the conservation conflict, from tangible and obvious aspects (biological, economic, physical, etc.) to intangible and latent aspects (psychological, social, political, etc.). Within this framework, one can analyze the stakeholders' satisfaction levels in relation to the wolf population, hinting at an optimal wolf population size, as a compromise between both sides of the conflict. This approach also allows for giving voice to the various stakeholders during the modelling process, which may facilitate communication and mutual understanding among stakeholders.

Results and analysis of our model simulation as well as observations and feedback from a stakeholder workshop are presented in "Results" and discussed in "Discussion," followed by final conclusions summarized in "Conclusion."

\section{Framing the stakeholder landscape}

Concerns of the main stakeholder groups involved in the wolf issue were extracted from the literature, using two main sources, Google scholar and the library of the Swedish University of Agricultural Sciences (where the first author is based). Key words used in our literature search included "wolf," "wolves," "Sweden," "Swedish," "attitude," "opinion," "wildlife management," "wildlife conservation," "wildlife conflicts," "conservation conflicts," "wildlife conflict model," "conservation model," "reservation model," "wildlife conflict resolution model," etc., used separately or in combination. After filtering out the most relevant papers, we retrieved about 220 articles and among them we used a few dozens of papers from which the stakeholder groups, their main attitudes and preferences, the drivers of the attitudes, the main conflicts, the policies, and the management history were extracted. Few articles directly use drivers to analyze the Swedish wolf problem, so to understand the drivers of the stakeholders in the conflicts, we use attitude as a proxy for a stakeholder stance in the wolf issue. Attitude can be defined as an individual's psychological tendency to evaluate a particular objective as favorable or unfavorable and consists of cognitive, affective, and conative components (Eagly and Chaiken 1993; Ajzen and Fishbein 2005; Dressel et al. 2015). This definition of attitude, which we use for our study, is only referential, as there is no standard definition or common understanding of the concept. The literature we found that describe attitudes in a wildlife conservation context usually explain also the reasons behind them, so those reasons can be regarded as drivers that lead to the attitudes.

We also carried out a series of interviews with some representatives of the identified stakeholder groups in 2014. Due to limited resources of our pilot study and the purpose of interviews being to provide a theoretical underpinning of our model, rather than to collect extensive data, assembling a representative s ample of interviewees was both unfeasible and unnecessary. Instead, interviewees were recruited mainly from the extended networks of contacts of authors and other researchers from the International Institute for Applied Systems Analysis (IIASA). The interviewees included 18 representatives from environmental non-governmental organizations, hunting organizations, farmers keeping livestock, Sami reindeer herders, and natural and social scientists who are working on the wolf issue in Sweden. Seven of the interviewees responded to our questions individually, the rest of the interviews were held during a small workshop. The questions asked during the interviews (collected in Appendix A in Supplementary Materials) focused mainly on attitudes towards the wolf and the concerns relating to the wolf population in Sweden.

We also held a one-and-a-half-day stakeholder workshop in Sigtuna, Sweden, in March 2018, organized in collaboration with the SEPA. The aim of the workshop was to engage communication and understanding among different stakeholders' groups and the scientists and governmental officials. The workshop included talks, discussions, participating modelling, and a role-playing game. Nineteen participants attended, representing environmentalists, hunters, livestock owners, scientists, and governmental officials. Modelling of stakeholder satisfaction function regarding the wolf population size was surveyed and discussed in the role-playing game section. There were three subsections of the role-playing section. In "Controversies around impacts of wolves," participants were paired with partners with opposite attitudes towards wolves. They (A) made statements about wildlife conservation and their partners (B) recorded the level of agreement, trust, and acceptance towards A. In "Policies on wolf conservation and 
societal response," participants were paired with partners with the same attitudes towards wolves and did the same process as "Controversies around impacts of wolves". In "Importance of the wolf population size in wolf management," participants were paired with partners with opposite attitudes towards wolves. They were required to assume their rivals' role and think with the same rationale as their rivals, and then, they did the same process as in "Controversies around impacts of wolves". Attitude surveys were done before, during, and after the workshop (Appendix B).

\section{Classification of the stakeholders}

Stakeholders are generally defined as any organization, group, or people who take interests in or are able to influence the outcomes of a project (Cundy et al. 2013; Reed et al. 2009). Some scholars (Doyle-Capitman et al. 2018) use a more specific definition in the situation of wildlife conservation, i.e., entities (organizations, networks and individuals) that (a) have interests in the case of conservation management (Gooden and Moir 2019), (b) may be influenced by the conservation process, and (c) have the ability to influence the process and the output of the conservation project. After the literature review and interviews with experts, and due to the theoretical base of our research, we determined to consider the major involved groups as the stakeholders in our analysis.

Previous studies have identified key stakeholder groups involved in wolf management all around the world with an emphasis on Europe and America. People living in urban areas, not owning livestock or reindeer, and who are not hunters, have been categorized as the general public (Dressel et al. 2015), urban public (Williams et al. 2002), urbanites (Heberlein and Ericsson 2005), or urban residents (Bruskotter et al. 2007). People, associated with organizations that advocate wolf reestablishment, have been categorized as conservationists (Bisi et al. 2010; Johansson and Karlsson 2011; Rogers 2014; Dressel et al. 2015), conservation groups (Stohr and Coimbra 2013), environmentalists (Sjölander-Lindqvist 2011), or even eco-warriors (Sjölander-Lindqvist et al. 2015). People practicing hunting activities are usually categorized as hunters, with or without dogs, or simply just hunters (Williams et al. 2002; Johansson and Karlsson 2011; Sjölander-Lindqvist 2011;
Stohr and Coimbra 2013; Dressel et al. 2015; SjölanderLindqvist et al. 2015). People owning livestock and living in rural areas are categorized as farmers (Williams et al. 2002; Johansson and Karlsson 2011; Sjölander-Lindqvist 2011; Sjölander-Lindqvist and Cinque, 2014; Dressel et al. 2015) or farm animal owners (Stohr and Coimbra 2013). People involved in reindeer herding in northern Sweden are often loosely described as Sami people, or just Samis (Rogers 2014; Sjölander-Lindqvist et al. 2015), although nowadays, most Samis are not reindeer herders (but all reindeer herders are Samis).

The stakeholder classification above is a convenient way to identify a minimal representative set of stakeholder groups in the Swedish society without compromising the diversity of viewpoints. From the above classification and combined with the stakeholder interviews, we have decided to use the following five stakeholder groups: (1) environmentalists, (2) urbanites, (3) hunters, (4) livestock owners, and (5) reindeer herders (Table 1$)$.

\section{Stakeholders' attitudes towards wolves}

Based on the literature review and interviews, we identify the most frequently mentioned attitudes that we think play the most important roles in the discussion over the management of the Swedish wolf population. As we are interested in a sustainable policy for wolf management, we classify factors that influence attitudes towards them into three categories, according to environmental, economic, and social aspects, which are the "three pillars" of sustainability. Definition of the stakeholders and their attitudes towards wolves are listed in Table 1.

The first category of the factors for the attitudes is based on environmental concerns, which involve knowledge and views on biodiversity from ecological sciences. The overriding factor is the value and function of the wolves to the ecosystem. The second category of factors shaping attitudes is based on economic considerations. They include loss of livestock, loss of game animals, loss of reindeer (Bostedt 1999), loss of hunting dogs (Rogers 2014), policies such as compensation and subsidized fencing (Williams et al. 2002), tax used for wolf protection, and ecotourism. The third category of factors affecting attitudes towards wolves is based

Table 1 Swedish stakeholder classification used in this study

\begin{tabular}{lll}
\hline Stakeholder & Definition & Attitude towards wolves \\
\hline Environmentalists & People from organizations that advocate wolf reestablishment & Strongly positive (pro-wolf) \\
Urbanites & People living in urban areas, not owning livestock or reindeer, and not hunters & Generally positive (pro-wolf) \\
Hunters & People practicing hunting activities & Strongly negative (anti-wolf) \\
Livestock owners & People owning livestock and living in rural areas & Negative (anti-wolf) \\
Reindeer herders & People involved in reindeer herding in northern Sweden (Samis) & Strongly negative (anti-wolf) \\
\hline
\end{tabular}


on social concern. To the prominent ones belong the fear of wolves (Johansson and Karlsson 2011) and feelings relating to hunting and Sami cultures, such as the notion of belonging to a certain social group or tradition (Naughton-Treves et al. 2003; von Essen and Allen 2015; Eriksson 2016). Some scholars also mention the disproportional power for different social groups in decision making, the urbanization, and decreasing employment in agriculture, which trigger some complaints in rural areas about the sacrifice of rurality for urbanization (Bisi et al. 2007; Røskaft et al. 2007). We think these can also be included into the factors of hunting and Sami cultures, because social identities, lifestyles, the feeling of being neglected, and disproportional empowerment can all be identified with their culture. Figure 2 visualizes how the abovementioned factors influence formation of perspectives and attitudes towards wolves.

Although in each stakeholder group there are people holding different attitudes to various degrees, we opt for representing only the most common attitudes held by the majority in each group. This simplification is justified, because the aim of this paper is to prove the concept of the presented framework through analysis of general trends which reflect reality with sufficient degree of fidelity (and not strive for the most detailed accuracy). Our interest in the general trends warrants further simplifications. As indicated in Table 1, we divide considered stakeholder groups into two main categories, that is the "pro-wolf" (wolf advocates) and the "anti-wolf" (wolf objectors) stakeholders (Sjölander-Lindqvist 2008). Urbanites and environmentalists, having mostly positive attitudes towards wolves, are hence aggregated into a "pro-wolf" group, while hunters, livestock owners, and reindeer herders, having generally negative attitudes towards wolves, are aggregated into an "anti-wolf" stakeholder group.

\section{Model of stakeholders' satisfaction}

Conservation conflicts fall into a broader category of environmental management issues. Traditional methods to analyze conflicts over environmental management, including wildlife management, have been summarized by Hipela and Walker (2011). The methods are there listed as follows: graph model for conflict resolution, multiple criteria decision analysis, fair resource allocation, normal form, and extensive form. Among these methods, an important element is to analyze the causes or drivers of the people for their claim in the conflicts.

Despite devoted efforts to mitigate the conservation conflicts all over the world, many of them remain persistent problems without successful solutions (Madden and McQuinn 2014). Soliku and Schraml (2018) found that the conservation conflicts in developing countries are primarily driven by factors regarding livelihood, while in developed countries more by psychological and social factors, such as emotional, recreational, and cultural values. We also observe in Sweden psychological and social factors play important roles in people forming attitudes towards wolves. One blind spot in the management of the conflicts
Fig. 2 A systematic representation of factors relevant to formation of attitudes towards wolves. To the left of the figure are the perspectives representing the "three pillars" of sustainable development. These categories cover eight different factors, presented in the middle column, that are linked to interests of various stakeholders. For the sake of clarity of the picture, other interests are listed in boxes representing different stakeholder groups

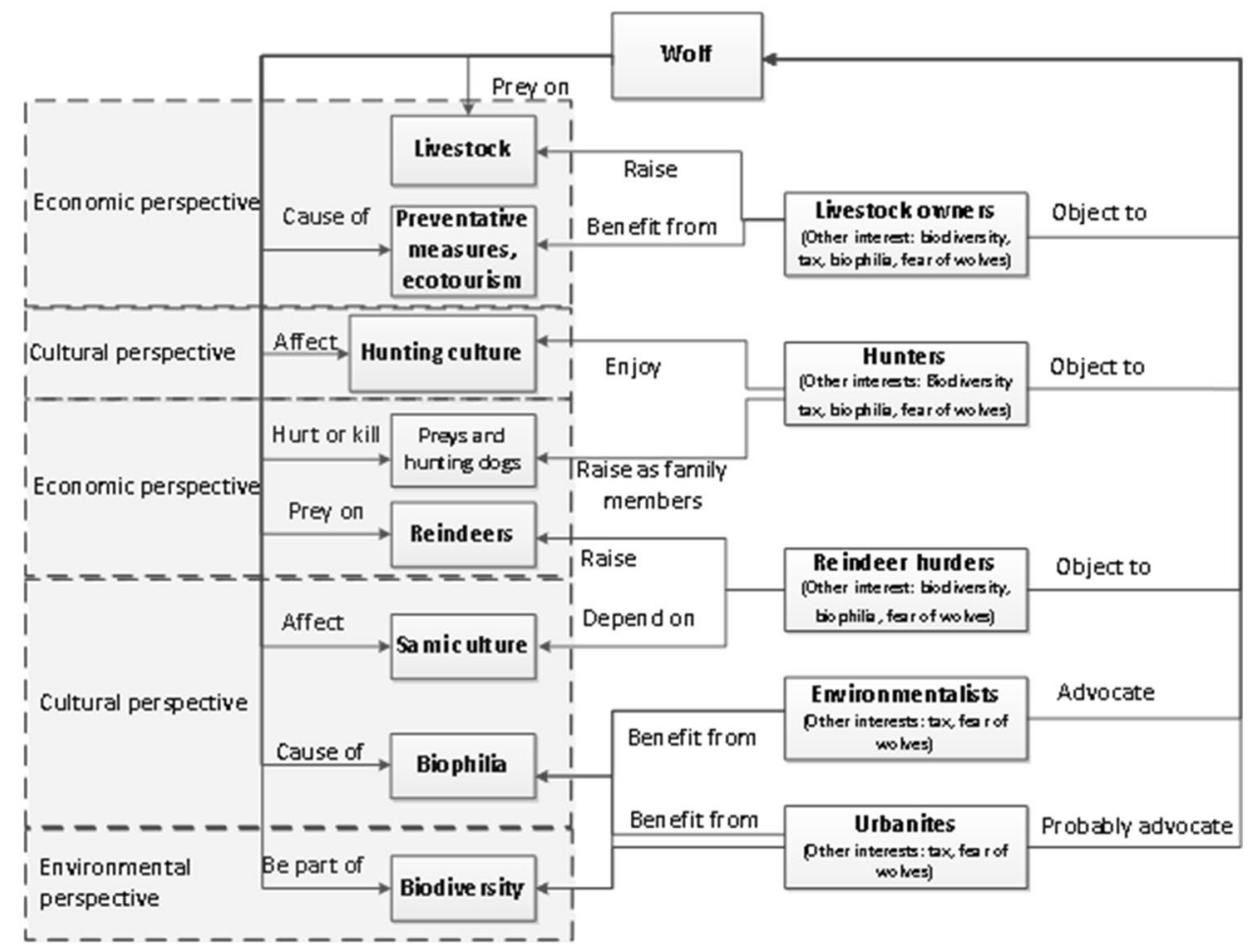


is that the decision makers usually focus on short-term, superficial solutions with regard to biological, economic, and physical factors and ignore the deeply rooted causes of social and psychological values and needs. Thus, the actions by the government often lead to temporal compromises with the potential conflicts lurking for future rebound. To effectively manage the conservation conflicts with sustainable effects, one should recognize deeply held values, high stakes, power imbalances, complexity, and sense of moral superiority that may lie behind the conflicts (Madden and McQuinn 2014).

Following this train of thought, Zimmermann et al. (2020) are proposing a framework of a three-level analytical structure of human-wildlife conflicts. From level 1 to level 3 , conflicts are classified from tangible and concrete forms, mostly relating to economy, belonging, and personal safety (level 1) to more abstract and ideological forms, like historically unfair political processes and tensions among different parties (level 2), and social identities and clashing values and beliefs (level 3). Using this framework to determine the current conflict level can improve the management practice, policy making and implementation, so it should be incorporated at the design stage of a conservation plan or intervention (Zimmermann et al. 2020). This novel framework is good at classifying the causes of the conflicts at different levels, but it does not go further to link the causes at different conflict levels to a potential wolf population acceptable to the conflicting sides. When using this framework, managers or coordinators have to discern which parts/processes of the conflicts belongs to which level, and take corresponding actions. However, sometimes several conflict levels can happen at the same time, which may lead to different or even conflicting conclusion on suggested wolf population. Therefore, this framework lacks integration of different aspects of the conflicts, weighting their significance and searching for a comprehensive solution.

Mason et al. (2018) classified conservation conflicts as wicked problems and suggested applying wicked approaches other than conventional measures. Among these suggested approaches, two approaches (pattern-based evidence and trade-offs in objectives) are related to finding the deeply rooted drivers of the stakeholder's decision-making and their relationships, as well as the development of optimizable trade-off-based objectives.

Given the complexity of the wolf issue and the myriad of stakeholder positions, classical methods, such as cost-benefit analysis, are not well suited to address it. Indeed, Jordan (2015) argues that the question of the wolf population size in Sweden touches upon people's feelings, beliefs, and values, making the discourse emotional rather than turning it into an objective negotiation of economic benefits and losses. This makes the stakeholders' perception of satisfaction (rather than some notion of utility expressed in monetary terms) a suitable currency of the analysis. In the "Introduction," we have summarized the main factors that influence the formation and the change of the attitudes of the stakeholders, so we consider satisfaction with the state of the factors listed in "Stakeholders' attitudes towards wolves" (environmental, economic and social) to be the important drivers of stakeholders' attitudes towards wolves.

In this section, we suggest a model that links the stakeholder's satisfaction level with the wolf population size. First, we propose a model based on partial satisfaction functions (see "Partial satisfaction functions"), describing the stakeholders' satisfaction - with individual factors which we consider to be important drivers of stakeholders' attitudes towards wolves. Next, we aggregate the partial satisfaction functions into an overarching satisfaction of each stakeholder group, making up total satisfaction functions discussed in "Total satisfaction functions for different stakeholders."

\section{Partial satisfaction functions}

As mentioned above, our hypothesis is that stakeholders' attitudes to wolves are driven by their satisfaction with certain social, economic and environmental factors influenced by the size of the wolf population. In order to quantitatively analyze the impact of wolf population on stakeholders' satisfaction with each of these factors we chose to measure it on the scale between 0 (full dissatisfaction) and 1 (level of full satisfaction, beyond which further improvements to the state of the factor have no effect on stakeholder's attitude towards wolves).

Having chosen a scale for a satisfaction level, we can now map the size of the wolf population, which influences the state of the considered factor, into stakeholder's satisfaction with the state of this factor - that is to define a partial satisfaction function. We devise basic forms of these functions based on our understanding from the literature and interviews. We first design the shapes of different relationships between satisfaction level and interest depending on the wolf population size, based on literature studies. Then, we show these shapes to the interviewees and asked for their opinion. We finalize the shapes on this basis. We believe that the generic functional forms that we suggest are reasonable representations for the purposes of this initial study and the model building. We propose curves with which we approximate the relations between the satisfaction level of one (or more) stakeholder group(s) regarding certain factors that drive the attitudes and the relevant wolf population (Table 2). The functional forms of the relations and the choice of parameters are discussed in Table 4 . The choice of these curves was primarily guided by the known satisfaction of stakeholder groups at benchmark values of wolf population size (e.g., absence of wolves, carrying capacity, favorable reference 
Table 2 Choice of partial satisfaction functions (dependent on the wolfs population size)

\begin{tabular}{|c|c|c|}
\hline $\begin{array}{c}\text { Partial } \\
\text { Satisfaction } \\
\text { function }\end{array}$ & Shape & Justification \\
\hline \multicolumn{3}{|r|}{ Environmental perspective } \\
\hline Biodiversity & & $\begin{array}{l}\text { When the wolf population is very small, its contribution to } \\
\text { biodiversity is minimal, thus the satisfaction level is close to zero. It } \\
\text { increases until the size of the wolf population reaches the carrying } \\
\text { capacity (CC) (Bruford 2015; Sjögren-Gulve and Hörnell- } \\
\text { Willebrand 2015). level and then stabilizes, approaching } 1 \text {. In this } \\
\text { study we consider sizes of wolf population that are much smaller } \\
\text { than carrying capacity and assume the sigmoid function as a model. } \\
\text { For larger sizes of the wolf population, the biodiversity satisfaction } \\
\text { function is likely to decrease, but it is not relevant to our } \\
\text { considerations here. }\end{array}$ \\
\hline Biophilia & & $\begin{array}{l}\text { According to the theory of biophilia, we assume that people would } \\
\text { like to see as many wolves as possible in nature, but the marginal } \\
\text { satisfaction would probably decrease until the wolf population } \\
\text { reaches some limit size, when the satisfaction levels off. An } \\
\text { exponential function is chosen to describe this dynamic. }\end{array}$ \\
\hline \multicolumn{3}{|r|}{ Economic perspective } \\
\hline $\begin{array}{l}\text { Loss of } \\
\text { livestock }\end{array}$ & & $\begin{array}{l}\text { More wolves implies that more livestock are attacked and killed. The } \\
\text { satisfaction would hence have its maximum value when there are no } \\
\text { wolves. When there are a few wolves, the satisfaction is relatively } \\
\text { high which means livestock owners would presumably have a } \\
\text { certain tolerance towards a small number of wolves. With a larger } \\
\text { number of wolves, the satisfaction would continue to decrease }\end{array}$ \\
\hline
\end{tabular}




\begin{tabular}{|c|c|}
\hline & towards zero. \\
\hline $\begin{array}{l}\text { Loss of } \\
\text { reindeer }\end{array}$ & $\begin{array}{l}\text { The rationale for choosing this function is similar to that of loss of } \\
\text { livestock, but the satisfaction should drop more quickly. Reindeer } \\
\text { herders are assumed to be more negative than livestock owners, } \\
\text { considering that reindeer herders in general depend solely on } \\
\text { reindeer herding, and the damage caused by wolves also involves } \\
\text { scattering of the herds, which is costly in itself. }\end{array}$ \\
\hline $\begin{array}{l}\text { Loss of } \\
\text { hunting } \\
\text { dogs }\end{array}$ & $\begin{array}{l}\text { Satisfaction here changes similarly as the above two functions. } \\
\text { However, hunters seem, in general, to have the least acceptance of } \\
\text { wolves, so the satisfaction here is suggested to drop most sharply. }\end{array}$ \\
\hline Tax & $\begin{array}{l}\text { If there are more wolves, taxpayers have to spend more money on } \\
\text { protecting the wolves and expenses relating to the compensation, } \\
\text { installing fences, etc. Hence, the satisfaction maximizes when the } \\
\text { wolf population is zero, and decreases as the wolves increase. }\end{array}$ \\
\hline $\begin{array}{l}\text { Preventative } \\
\text { measures }\end{array}$ & $\begin{array}{l}\text { Preventive measures are used to protect livestock, hunting dogs, and } \\
\text { reindeers from wolf attacks. The compensation for the losses of dead } \\
\text { or wounded animals and the damage of infrastructure also belongs to } \\
\text { this category. However, the current preventative measures are } \\
\text { claimed by the stakeholders to be far too insufficient to cover the } \\
\text { whole loss, especially for the emotional and social perspectives. } \\
\text { Therefore, more wolves are expected to lead to more losses and less } \\
\text { satisfaction. With no wolves, the satisfaction level is assumed to be } \\
\text { at maximum. As the wolf population grows, the satisfaction would } \\
\text { presumably decrease to zero, when the wolf population is very large. }\end{array}$ \\
\hline Ecotourism & $\begin{array}{l}\text { When the wolf population is small and the chance for spotting a wolf } \\
\text { or its tracks is low, ecotourism markets wolves makes little profit. } \\
\text { Thus, the satisfaction of people both doing business and enjoying the } \\
\text { services is very low. As the wolf population grows, the satisfaction }\end{array}$ \\
\hline
\end{tabular}


Table 2 Continued

\begin{tabular}{|c|c|}
\hline & $\begin{array}{l}\text { increases. However, the satisfaction level would not increase linearly } \\
\text { because when there are too many wolves that could be easily } \\
\text { observed or encountered, people would become reluctant to pay for } \\
\text { ecotourism. So, the marginal satisfaction will presumably decrease } \\
\text { and the satisfaction level will remain almost constant. }\end{array}$ \\
\hline \multicolumn{2}{|r|}{ Social perspective } \\
\hline Fear & $\begin{array}{l}\text { Frank, Johansson, and Flykt (2015) found that the fear of wolves } \\
\text { links to the abundance of wolves. When wolves are absent, there is } \\
\text { no fear and the satisfaction is highest. As the population increases, } \\
\text { the fear may increase linearly, rendering a linear decrease of the } \\
\text { satisfaction. }\end{array}$ \\
\hline $\begin{array}{l}\text { Hunting } \\
\text { culture }\end{array}$ & $\begin{array}{l}\text { The hunting culture would be best preserved when there is no } \\
\text { disturbance, i.e., with no wolves in the vicinity. Thus, the } \\
\text { satisfaction is highest when there is no wolf. The satisfaction drops } \\
\text { when the wolf number increases. When the wolf population is very } \\
\text { large, the satisfaction gradually becomes almost zero. }\end{array}$ \\
\hline $\begin{array}{l}\text { Sami } \\
\text { culture }\end{array}$ & $\begin{array}{l}\text { The satisfaction level for the Sami culture would decrease as the } \\
\text { wolf population increases, reaching zero satisfaction at a very larger } \\
\text { population. }\end{array}$ \\
\hline
\end{tabular}

population) and a general principle of using the simplest possible functional form. A favorable reference population (FRP) in a given biogeographical region is an indicator for the minimum population size necessary to ensure long-term viability of the species (European Commission 2005). For the wolves in Sweden, the FRP is conceived to be around 500 (Bruford 2015; Sjögren-Gulve and HörnellWillebrand 2015).

We use carrying capacity (CC) instead of favorable reference population (FRP) to set the upper limit of the wolf population. During the interview with the stakeholder, we found that wolf advocates tended to use $\mathrm{CC}$ to argue for increasing wolf population to an ideal volume while wolf objectors were more inclined to use FRP to argue for population control. Since the interests of biodiversity, biophilia, and ecotourism link to the positive consideration of the wolf, we consider it more proper to use CC as the maximum population wanted by wolf advocates. The environmental carrying capacity of wolves in Sweden has been estimated to be around 10,000 (Persson 1996). However, in 1800 , the wolf population in Sweden was about 1500 , which was considered too many for the country and the wolves were taken as pests at that time. Sand et al. (2014) suggested that the carrying capacity in modern Sweden should be about 1200 wolves, outside the reindeer herding area. From the above information, we take 1200 wolves 
as a reasonable (tentative) carrying capacity in our model. We also assume that when stakeholders form their attitudes in relation to the wolf population, they would use the same carrying capacity no matter what factor is considered, which means the upper limit of the wolf population in all the satisfaction functions about all the factors are set uniformly to 1200 .

\section{Total satisfaction functions for different stakeholders}

Because of the importance of each factor influencing the final attitude differs, we use the weight of each partial satisfaction function in the aggregative final satisfaction to indicate the importance. Based on stakeholder interactions and expert assessment, the weights are elicited in Table 3. The relative weights given here are conceptual (low, medium, high), only corresponding roughly to the importance of the factors rating by the stakeholders. The qualitative weights are translated to quantitative numbers, as Low $=[0,0.05)$, Medium $=[0.05$, 0.2 ), and High $=[0.2,1]$. (See Table 5 for the exact values used in each function.) For each stakeholder group, the sum of all weights is 1 .

By summing the weights of the different factors, a general satisfaction function for each stakeholder, with respect to the wolf population, is formed. Excluding factors with weight of 0 , the satisfaction function for environmentalists and urbanites (the "pro-wolf" group) is summed up as follows:

$$
S_{P r o}=w_{B d_{-} P} S_{B d}+w_{T_{-} P} S_{T}+w_{B p h_{-} P} S_{B p h}+w_{F_{-} P} S_{F}
$$

$S_{P r o}$ denotes the total satisfaction level of the "pro-wolf" stakeholders. $S_{B d}, S_{T}, S_{B p h}$, and $S_{F}$ denote the satisfaction levels influenced by the concern of biodiversity, tax, biophilia, and fear of wolves, respectively. $w_{B d_{-} P}, w_{T_{-} P}, w_{B p h_{-} P}$, and $w_{F_{-} P}$ denote the weights of $S_{B d}, S_{T}, S_{B p h}$ and $S_{F}$ in calculating the total satisfaction level $S_{P r o}$.

The satisfaction function for hunters is as follows:

$$
\begin{aligned}
S_{H} & =w_{B d \_H} S_{B d}+w_{T \_H} S_{T}+w_{\text {Loss_hun }} S_{\text {Loss_hun }}+w_{E c o} S_{E c o} \\
& +w_{B p h \_H} S_{B p h}+w_{F \_H} S_{F}+w_{H u n \_c u l} S_{H u n \_c u l}
\end{aligned}
$$

$S_{H}$ denotes the total satisfaction level of hunters. $S_{\text {Loss_hun }}$, $S_{E c o}$, and $S_{\text {Hun_cul }}$ denote the satisfaction levels influenced by the concern of loss of hunting dogs, ecotourism, and hunting culture, respectively. $w_{B d_{-} H}, w_{T_{-} H}, w_{\text {Loss_hun }}, w_{E c o}, w_{B p h_{-} H}$, $w_{F_{-} H}$, and $w_{H u n \_c u l}$ denote the weights of $S_{B d}, S_{T}, S_{\text {Loss_hun }}$, $S_{E c o}, S_{B p h}, S_{F}$, and $S_{H u n \_c u l}$ respectively in calculating $S_{H}$.

The satisfaction function for livestock owners is as follows:

$$
\begin{aligned}
S_{L} & =w_{B d \_L} S_{B d}+w_{T_{-} L} S_{T}+w_{\text {Loss_liv }} S_{\text {Loss_liv }}+w_{\text {Pre }} S_{\text {Pre }} \\
& +w_{\text {Bph_L }} S_{\text {Bph }}+w_{F \_L} S_{F}
\end{aligned}
$$

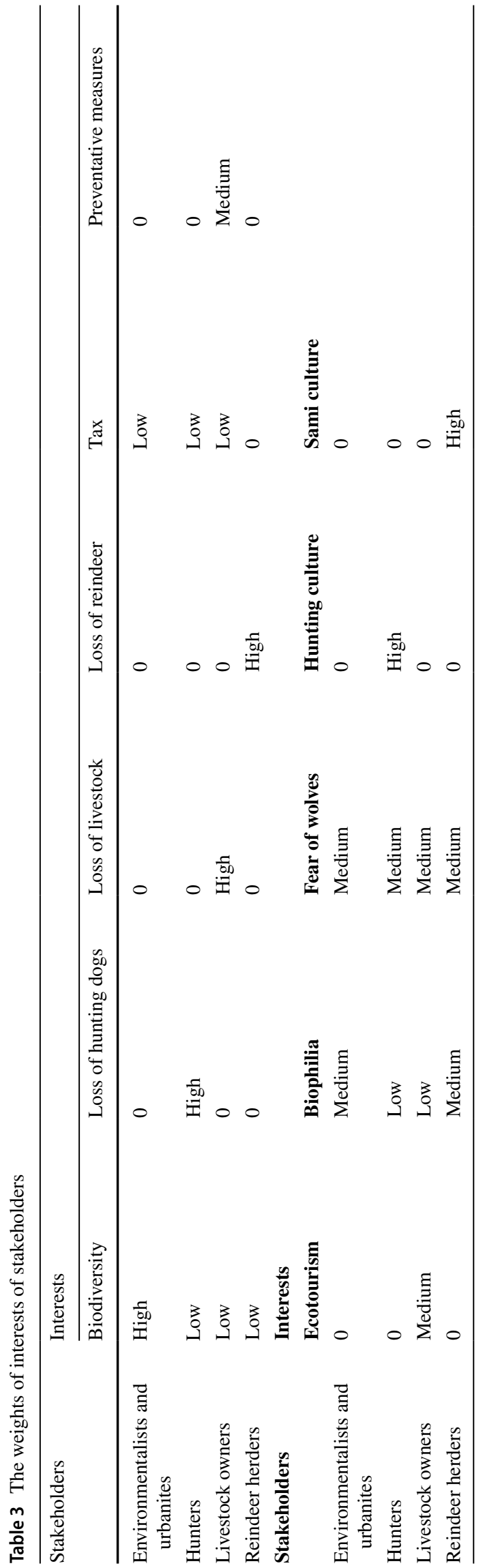


Table 4 Parametrization of partial satisfaction functions. Each partial satisfaction factor is a function of wolf population size $n$

\begin{tabular}{|c|c|c|}
\hline Partial satisfaction factor & Formula & Choice of parameters \\
\hline Biodiversity & $\mathrm{S}_{B d}(n)=\frac{1}{1+e^{-a(n-\mu)}}$ & $\begin{array}{l}\mu \text { is the location parameter (point at which the value of the sigmoid function } \\
\text { is equal to 0.5). We set } \mu=500 \text { which is the favorable reference popula- } \\
\text { tion (Bruford, 2015; Sjögren-Gulve and Hörnell-Willebrand, 2015) } \\
a \text { is the shape parameter regulating rate of increase of the function. Here we } \\
\text { set } a=0.01358 \text {, so that } S_{B d}(0)=0.01 \text { and } S_{B d}(\mu)=0.9\end{array}$ \\
\hline Biophilia & $S_{B p h}(n)=1-e^{-c_{1} n}$ & $\begin{array}{l}c_{1} \text { is the coefficient describing how quickly the satisfaction function grows } \\
\text { from zero }\left(s^{\prime}(0)=c_{1}=0.009\right)\end{array}$ \\
\hline Loss of livestock & $S_{\text {Loss_liv }}(n)=e^{-c_{2} n^{2}}$ & $\begin{array}{l}c_{2}=0.00001 \text { is the coefficient describing how quickly the satisfaction func- } \\
\text { tion decreases from } 1 \text { (for zero wolves) }\end{array}$ \\
\hline Loss of reindeer & $S_{\text {Loss_rei }}(n)=e^{-c_{3} n^{2}}$ & $c_{3}=0.00005$ \\
\hline Loss of hunting dogs & $S_{\text {Loss_hun }}(n)=e^{-c_{4} n^{2}}$ & $c_{4}=0.0001$ \\
\hline $\operatorname{Tax}$ & $S_{T}(n)=e^{-c_{5} n^{2}}$ & $c_{5}=0.0000005$ \\
\hline Preventative measures & $S_{P r e}(n)=e^{-c_{6} n^{2}}$ & $c_{6}=000,001$ \\
\hline Ecotourism & $S_{E c o}(n)=1-e^{-c_{7} n}$ & $\begin{array}{l}c_{7} \text { is the coefficient describing how quickly the satisfaction function grows } \\
\text { from zero }\left(S^{\prime}(0)=c_{7}=0.009\right)\end{array}$ \\
\hline Fear & $S_{F}(n)=1-k n$ & $\begin{array}{l}k \text { is the coefficient describing how quickly the satisfaction function } \\
\text { decreases from zero }\left(S^{\prime}(0)=k=0.000769\right) \text {. The value of } k \text { is set arbitrar- } \\
\text { ily to fit the curve }\end{array}$ \\
\hline Hunting culture & $S_{H u n \_c u l}(n)=e^{-c_{8} n}$ & $\begin{array}{l}c_{8} \text { is the coefficient describing how quickly the satisfaction function } \\
\text { decreases from } 1 \text { (for zero wolves) }\end{array}$ \\
\hline Sami culture & $S_{\text {Sam_cul }}(n)=e^{-c_{9} n}$ & $c_{9}=0.003$ \\
\hline
\end{tabular}

$S_{L}$ denotes the total satisfaction level of livestock owners. $S_{\text {Loss_liv }}$ and $S_{\text {Pre }}$ denote the satisfaction levels influenced by the concern of loss of livestock and preventative measures. $w_{B d_{-} L}, w_{T_{-} L}, w_{\text {Loss_liv }}, w_{P r e}, w_{B p h_{-} L}$, and $w_{F_{-} L}$ denote the weights of $S_{B d}, S_{T}, S_{\text {Loss_liv }}, S_{P r e}, S_{B p h}$, and $S_{F}$ respectively in calculating $S_{L}$.

The satisfaction function for reindeer herders is as follows:

$$
\begin{aligned}
S_{R} & =w_{B d \_R} S_{B d}+w_{T \_R} S_{T}+w_{\text {Loss_rei }} S_{\text {Loss_rei }}+w_{B p h_{-} R} S_{B p h} \\
& +w_{F \_R} S_{F}+w_{\text {Sam_cul }} S_{\text {Sam_cul }}
\end{aligned}
$$

$S_{R}$ denotes the total satisfaction level of reindeer herders. $S_{\text {Loss_rei }}$ and $S_{\text {Sam_cul }}$ denote the satisfaction levels influenced by the concern of loss of reindeer and Sami culture. $w_{B d_{-} R}$, $w_{T_{-} R}, w_{\text {Loss_rei }_{-}}, w_{B p h_{-} R}, w_{F_{-} R}$, and $w_{\text {Sam_cul }}$ denote the weights of $S_{B d}, S_{T}, S_{\text {Loss_rei }}, S_{B p h}, S_{F}$, and $S_{\text {Sam_cul }}$ respectively in calculating $S_{R}$.

The total satisfaction functions of hunters, livestock owners, and reindeer herders are similar in shape thus we group them together as "anti-wolf" group and model their joint satisfaction level simply as the average for this pilot study. The satisfaction function for the "anti-wolf" group is as follows:

$S_{\text {Anti }}=\left(S_{H}+S_{L}+S_{R}\right) / 3$

$S_{\text {Anti }}$ denotes the satisfaction level of "anti-wolf" stakeholders.

\section{Results}

We analyze jointly the total satisfaction level on "anti-" and "pro-wolf" stakeholders regarding the wolf population in order to identify the range within which a compromise solution can be found. We consider two "extreme" concepts of satisfaction for the social welfare. The "egalitarian" approach seeks to maximize the satisfaction level of the least satisfied stakeholder group (which leads, eventually, to equalization of satisfaction levels of considered stakeholders' groups). However, by doing so, it tends to disregard the satisfaction of other stakeholder groups. On the other end of the spectrum is the so-called utilitarian approach aiming at a maximization of the overall satisfaction of the whole society (Binmore 1998) (defined as the sum of the satisfaction levels of concerned stakeholder groups). This approach prioritizes stakeholders whose satisfactions are already high or easiest to improve (relatively to other stakeholder groups) and thus potentially neglects the needs of more dissatisfied stakeholders.

The left panel of Fig. 3 visualizes the dependence of the total satisfaction of the pro-wolf stakeholders (orange line) and anti-wolf stakeholders (blue line) on the size of wolf population. The choice of parameters comprising the satisfaction functions is presented in Table 4, and the weights of these factors are given in Table 5. The egalitarian solution (marked by a diamond symbol) equalizes the satisfaction level of both stakeholder groups, suggesting 
Table 5 Exact values of weights used in Table 3

\begin{tabular}{|c|c|c|c|c|c|c|}
\hline \multirow[t]{2}{*}{ Stakeholders } & \multicolumn{6}{|l|}{ Interests } \\
\hline & Biodiversity & Loss of hunting dogs & Loss of livestock & Loss of reindeer & $\operatorname{Tax}$ & $\begin{array}{l}\text { Preven- } \\
\text { tative } \\
\text { measures }\end{array}$ \\
\hline Environmentalists and urbanites & 0.75 & 0 & 0 & 0 & 0.01 & 0 \\
\hline Hunters & 0.01 & 0.53 & 0 & 0 & 0.01 & 0 \\
\hline Livestock owners & 0.01 & 0 & 0.81 & 0 & 0.01 & 0.05 \\
\hline Reindeer herders & 0.01 & 0 & 0 & 0.5 & 0 & 0 \\
\hline \multirow[t]{2}{*}{ Stakeholders } & \multicolumn{6}{|l|}{ Interests } \\
\hline & Ecotourism & Biophilia & Fear of wolves & Hunting culture & Sami culture & \\
\hline Environmentalists and urbanites & 0 & 0.1 & 0.14 & 0 & 0 & \\
\hline Hunters & 0 & 0.01 & 0.05 & 0.39 & 0 & \\
\hline Livestock owners & 0.05 & 0.02 & 0.05 & 0 & 0 & \\
\hline Reindeer herders & 0 & 0.05 & 0.05 & 0 & 0.39 & \\
\hline
\end{tabular}

around 200 wolves. However, adopting this solution may result in a sharp decrease of the satisfaction of pro-wolf stakeholders (from 0.65 to 0.35 ), while improving the satisfaction of the anti-wolf group only slightly (from 0.2 to $0.35)$. The utilitarian solution (marked by a star symbol) suggests approximately 600 wolves. It favors the pro-wolf stakeholders (improving their satisfaction level from 0.65

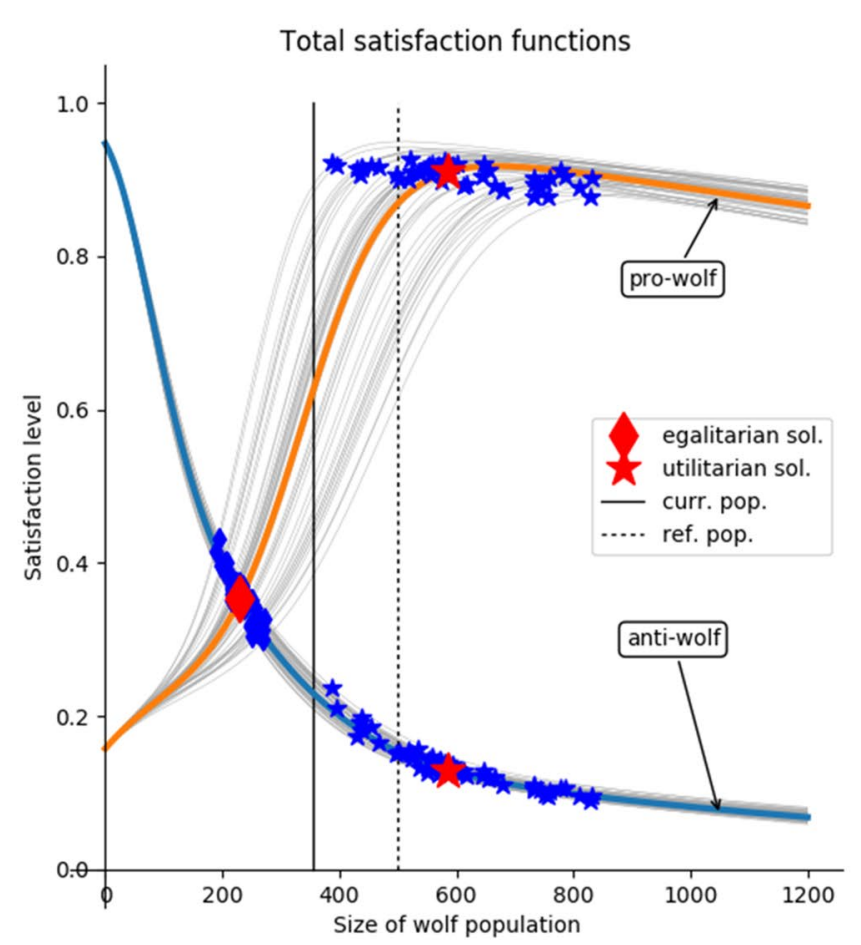

Fig. 3 Satisfaction levels of anti- and pro-wolf stakeholders. Increasing the size of wolf population to the carrying capacity $(\mathrm{CC})$ would significantly increase the satisfaction level of pro-wolf stakeholders while leaving anti-wolf stakeholders still more dissatisfied. Reduc- to 0.9 ) at the expense of causing further (but smaller in absolute terms) dissatisfaction among anti-wolf stakeholders (from 0.2 to 0.1 ).

The right panel of Fig. 3 presents the comparison of the attitudes of pro-wolf stakeholders against the satisfaction level of the anti-wolf stakeholders. An ideal situation, when both stakeholder groups are fully satisfied $(S=1$ for both

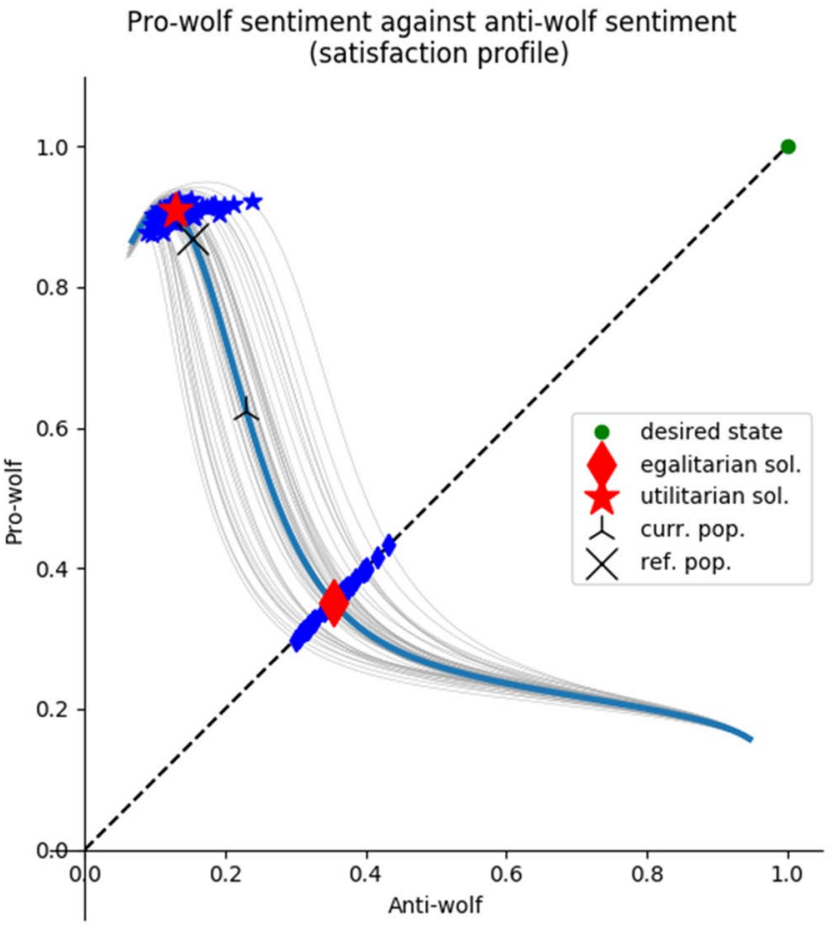

ing the population size to the point of equal satisfaction would leave both groups equally dissatisfied. No win-win solutions are possible as for any wolf population size the satisfaction profile is far away from a desired state of equal and full satisfaction of both groups 
Fig. 4 Sensitivity of results on choice of parametrization. On the horizontal axis is the variability of parameters relative to the originally assumed values, and on the vertical axis is the optimal size of the wolf population according to the egalitarian (blue ranges in the bottom part of the figure) and utilitarian (orange ranges in upper part of the figure) approaches. The Egalitarian solutions exhibit remarkable robustness to changes in parameter values. Uncertainty of the utilitarian solution grows significantly as we let parameters to deviate from the originally assumed values by $40 \%$ or more

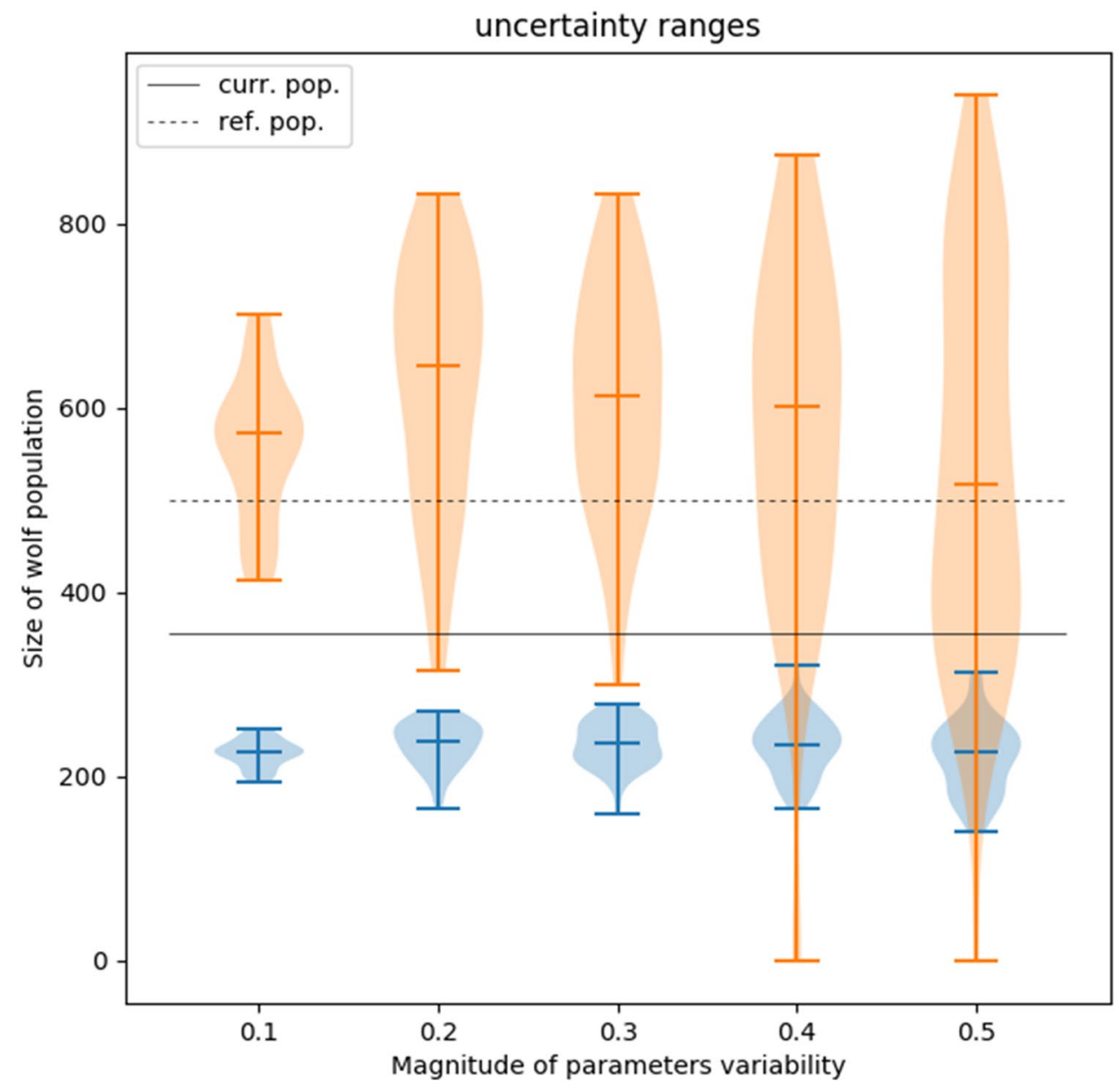

groups), is marked with a dot. Unfortunately, for any size of the wolf population, the outcome is far away from this ideal (in Euclidean distance) but corresponds approximately to the status quo, i.e., a wolf population of about 365 individuals (Naturvårdsverket 2020), as well as to the favorable reference population of about 500 individuals (Bruford 2015; Sjögren-Gulve and Hörnell-Willebrand 2015).

To address the inherent uncertainty of the satisfaction function parametrization, we perform a sensitivity analysis. Gray lines in Fig. 3 represent results of the analysis repeated 50 times under randomized values of the parameters - here drawn uniformly from intervals centered around the original value of the parameters by $\pm 20 \%$. This sensitivity analysis suggests that our findings are qualitatively robust, i.e., the conclusions we draw from the analysis are similar, although ranges of potential compromise span between egalitarian and utilitarian solutions change somewhat. In particular, the egalitarian solution (blue diamonds) is relatively stable (approx. 200 individuals) while the position of the utilitarian solution (blue stars) varies within a range from 400 to 800 individuals. Nevertheless, according to the egalitarian approach the optimal size of the wolf population is smaller than the current level, while the utilitarian approach suggests increasing the number of wolves with respect to status quo. As Fig. 4 suggests, such robustness of our findings holds true for parameter variability up to $30 \%$. If the uncertainty of parameter values is approximately $40 \%$ or larger, then the uncertainty of our findings grows significantly with the egalitarian and utilitarian solutions potentially swapping their relative position.

\section{Discussion}

This paper presents a stakeholder analysis supplemented by illustrative modelling for systematic analysis of the conflicting drivers related to the wolf management issue in Sweden. In this case, the conservation conflict not only relates to the economical and physical loss but also touches some deeper and more profound issues regarding identity, respect, value, trust, and historical conflicts between different social groups (Eriksson 2017a, b; Matti and Sandström 2011, 2013; Nilsson et al. 2020; Eriksson et al. 2015; Sjölander-Lindqvist 2008). Strong policies, such as a hunting ban and economic compensation, can only scratch the surface of the conflict and the effect is only for short-term. To find a sustainable solution, 
one should recognize and address the drivers behind the stakeholders' claims (Madden and McQuinn 2014). Our framework in this paper demonstrates a novel method to investigate and analyze the drivers of the stakeholders and to measure quantitatively the fulfilment of their drivers with the aid of satisfaction functions.

Regarding sustainable wildlife management, the population number is inevitably an important target in order to understand the demands of the various stakeholders. The results of the "Results" section indicate a wolf population size at which all sides are comparatively (dis)satisfied, but the importance is not in the specific number but rather in the process to explore how it is achieved and the various trade-offs. A solution to the conflict is not only setting a best limit on the number of wolves. It is also about policies to be implemented. Such policies will likely change attitudes/ satisfaction of the considered stakeholders. Yet, our model is well suited for this dynamic setting since changes in attitudes or satisfaction can be reflected by a relatively straightforward re-parametrization of partial satisfaction functions.

A systematic analytical framework which depicts the relation between the stakeholder satisfaction levels and the wildlife population is a useful tool to observe the severity of the conflict (from the discrepancy on the satisfaction) and the space for making compromise. Research on wildlife conservation conflicts seldom focuses on building a systematic framework to analyze the decision-making mechanism among the different stakeholders with an emphasis on attitudes and effects of potential policies (Anderson et al, 2005). As a decision maker, one can also use the framework analyze scenarios of different policies on the satisfaction levels and hence explore possible solutions to the conflict.

Furthermore, this approach can also be a useful tool for communication and collaboration. During the process of designing and modifying the functions, meetings, workshops, interviews, and other forms of unofficial dialogues can be held to further inform the modelling functions. Through these forms of communication and collaboration, stakeholders and experts can convene and discuss around a common platform. Being aware of the satisfaction functions of each other, people may come to understand each other in a more objective and rational way than in traditional meetings, which so far have failed to bring about agreement among stakeholders in the Swedish society. Useful information and knowledge from experts and the government can be shared among stakeholders. The outcome of the stakeholder workshop in Sigtuna, Sweden, suggests that participation of stakeholders inmodeling exercises, such as the one discussed in this paper, has a potential to de-emotionalize the conflicting sides and help them acquire a better understanding of the issue as an integrated system (Pidd 2010; Sterman 2001), be more sympathetic to each other, and focus on the solution instead of winning debates.
The modelling approach assumes a static relation between the satisfaction and the wildlife population. Unless a sudden big event happens, people's attitudes seem to be stable in a certain period (Ericsson and Heberlein 2003; Bruskotter et al. 2007). In fact, studies on the relations between time and attitudes towards wolves have not been effective at reaching agreements (Eriksson 2013; Treves et al. 2013; Eriksson et al. 2015). Future research could focus on scenarios with different policies or expected future events. If surveys of stakeholders' attitudes are collected regularly, then a time function can be included in the analysis.

The values towards wildlife are deeply rooted and persistent, despite wider social movement (Manfredo and Dayer 2004; Manfredo et al 2016, 2017). Therefore, it is reasonable to assume that the root of the conflict regarding wolf management lies on wildlife values: egalitarian vs utilitarian (von Essen 2017; Heberlein and Ericsson 2005, 2008; Peterson et al. 2019). In our model simulation, we also take into account the values of the stakeholders. With scenario analyses, our model will inform policy makers how to design suitable policies to dilute the impact of values, i.e., to decrease the weights of values in the satisfaction functions.

Regarding the selection of drivers being analyzed in this paper, some scholars argue that deeply rooted utilitarian views of wildlife play important roles in attitude formation towards wolves (Manfredo et al. 2016; Manfredo et al. 2017). However, even the most extreme utilitarians can be positive towards wolves, if they can gain any benefit from them. Therefore, utilitarian views are not counted as drivers in the conflicts. Hamilton et al. (2020) found that political identity plays a dominant role in predicting individual's opinions on wolves. Social networks or friends from the same political party make strong social political effects. However, we do not include this factor as a driver in our study, because we already consider stakeholder groups instead of individuals as the player in our functions. For individuals, affect from the same group members may be a main driver of attitudes, but for groups, this factor is less critical.

In practice, our model can be used for guiding policy making and conflict resolution. For policy makers, they can use the model to plan wolf population control and compensation strategies. For coordinators for the wolf conference with stakeholders, they can present the model as a tool to motivate rational discussion in a systematic framework. To ensure that the framework is applied properly and effectively, meaningful and comprehensive communication between stakeholders and scientists is necessary throughout the whole modeling process. Voices should be heard and expressions should be encouraged. Meetings and interviews should be carefully planned and organized to avoid exacerbation of the conflict and "discursive closure," to achieve a sufficient level of communicative capacity (Hallgren and Westberg 2015). 
While the novelty of this research is the development of a proof of concept, further research with appropriate data is needed for calibration of the satisfaction functions. For simplification, we lumped up stakeholders into five stakeholder groups and finally into two groups with pro- and anti-attitudes, disregarding the fact that within a classification, individuals may have very different attitudes which cannot simply be described by the same satisfaction function. In future studies, a more specific classification with a more complete spectrum of stakeholder groups should be considered. The drivers of the stakeholders' functional forms and related weights, and the relationships between satisfaction levels and the wolf population were drawn and inferred from a limited number of meetings and discussions we held with experts and stakeholders. The scope of these meetings and interviews is constrained and a sample size at a national level is missing. These drawbacks should be complemented with detailed and thorough field studies that include additional interviews and surveys, as well as a census or estimation of the size of stakeholder group. With these data, in an advanced version of the model, the influence of each stakeholder group on the total satisfaction level of pro- and anti- wolf groups will be addressed by using a weighted population before the satisfaction function of each stakeholder group $\left(S_{H}, S_{L}\right.$, and $\left.S_{R}\right)$ in the total satisfaction level $\left(S_{\text {Anti }}\right)$ in Formula 5.

Furthermore, the suggested framework can be applied to other contested social issues, such as climate change, land use planning, or refugee and immigration issues. More systematic methodologies are called for in the future, especially models to simulate the interaction between stakeholders.

\section{Conclusion}

In conclusion, this paper presents a systematic framework for analyzing the drivers of stakeholders with conflicting attitudes regarding wildlife management. The framework uses satisfaction functions to model the relationships between the drivers of stakeholders and the wolf population in Sweden. With information from the literature, we developed our satisfaction functions in dialogue with experts and stakeholder representatives. The entire process of distilling components, naming them, defining their qualitative relation with the wolf size and - only at the last step - using simple functional forms to represent those qualitative relations for illustrative purposes is the valuable method of translating a wicked problem into a well-structured one. In this translation, complexity is radically reduced but as the translation is supported by good evidence - the model still represents the "reality" to a satisfactory degree.

We believe that this modelling approach can be used as an analytical tool for studying the psychological drivers of stakeholders in conflict, as well as the effects of different policy measures on changes of stakeholder attitudes. It can also serve as a basis for discussion and dialogue between stakeholders where different viewpoints can be expressed and discussed with the aim of reaching a more balanced and acceptable solution. Wolf management in Sweden is only one test of this approach. We believe that our method can be useful for other issues in wildlife conservation and even in other social issues in which stakeholders hold conflicting views.

Supplementary information The online version contains supplementary material available at https://doi.org/10.1007/s10344-021-01495-1.

Funding Open access funding provided by Swedish University of Agricultural Sciences.

\section{Declarations}

Conflict of interest The authors declare no competing interests.

Disclaimer The authors alone are responsible for the content and writing of this article.

Open Access This article is licensed under a Creative Commons Attribution 4.0 International License, which permits use, sharing, adaptation, distribution and reproduction in any medium or format, as long as you give appropriate credit to the original author(s) and the source, provide a link to the Creative Commons licence, and indicate if changes were made. The images or other third party material in this article are included in the article's Creative Commons licence, unless indicated otherwise in a credit line to the material. If material is not included in the article's Creative Commons licence and your intended use is not permitted by statutory regulation or exceeds the permitted use, you will need to obtain permission directly from the copyright holder. To view a copy of this licence, visit http://creativecommons.org/licenses/by/4.0/.

\section{References}

Ajzen I, Fishbein M (2005) The influence of attitudes on behavior. In: Albarracín D, Johnson BTM, Zanna P (eds) The handbook of attitudes. Psychology Press, New York, pp 173-221

Andersson T, Bjärvall A, Blomberg M (1977) Inställningen till Varg i Sverige - en intervjuundersökning. Statens Naturvårdsverk, Stockholm

Anderson RA, Crabtree BF, Steele DJ, McDaniel RR Jr (2005) Case study research: the view from complexity science. Qual Health Res 15(5):669-685

Arnbom T (2011) The wolf hunt in Sweden 2010 and 2011. http://www. wwf.se/wwfs-arbete/arter/1335783-the-wolf-hunt-in-sweden-2010and-2011. Accessed 25 October 2017

Berg L, Solevid M (2015) Tracing a political cleavage: the wolf issue in Sweden. European Politics Soc 16(4):488-522

Binmore K (1998) Egalitarianism versus utilitarianism. Utilitas 10(03):353-367

Bisi J, Kurki S, Svensberg M, Liukkonen T (2007) Human dimension on wolf (Canis lupus) conflicts in Finland. Eur J Wildlife Res 53:304-314

Bisi J, Liukkonen T, Mykrä S, Pohja-Mykrä M, Kurki S (2010) The good bad wolf - wolf evaluation reveals the roots of the Finnish wolf conflict. Eur J Wildlife Res 56:771-779

Bostedt G (1999) Threatened species as public goods and public bads - an application to wild predators in Sweden. Environ Resource Econ 13:59-73 
Bostedt G, Grahn P (2008) Estimating cost functions for the four large carnivores in Sweden. Ecol Econ 68:517-524

Brown T, Decker D (1979) Incorporating farmers' attitudes into management of white-tailed deer in New York. J Wildlife Manage 43(1):236-239

Bruford MW (2015) Additional population viability analysis of the scandinavian wolf population. Swedish Environmental Protection Agency, Stockholm

Bruskotter JT, Schmidt RH, Teel TL (2007) Are attitudes toward wolves changing? A case study in Utah. Biol Conserv 139:211-218

Castle S (2015) Wolves, resurgent and protected, vex Swedish farmers. https://www.nytimes.com/2015/08/16/world/europe/wolvesresurgent-and-protected-vex-swedish-farmers.html?_r=0. Accessed 08 March 2017

Cilliers P (1998) Complexity and postmodernism: understanding complex systems. Routledge, New York

Creel S, Christianson D (2007) Relationships between direct predation and risk effects. Trends Ecol Evol 23:194-201

Cundy AB, Bardos RP, Church A, Puschenreiter M, Friesl-Hanl W, Müller I, Neu S, Mench M, Witters N, Vangronsveld J (2013) Developing principles of sustainability and stakeholder engagement for "gentle" remediation approaches: the European context. J Environ Manage 129:283-291

Decker D, Purdy K (1988) Toward a concept of wildlife acceptance capacity in wildlife management. Wildlife Soc B (1973-2006) 16(1):53-57

Doyle-Capitman CE, Decker DJ, Jacobson CA (2018) Toward a model for local stakeholder participation in landscape-level wildlife conservation. Hum Dimens Wildl 23(4):375-390

Dressel S, Sandström C, Ericsson G (2015) A meta-analysis of studies on attitudes toward bears and wolves across Europe 1976-2012. Conserv Biol 29(2):565-574

Eagly AH, Chaiken S (1993) The psychology of attitudes. Harcourt Brace Jovanovich College, Orlando

Eriksson M (2013) Attitude stability in a changing carnivore context: the foundations of attitudes towards the Swedish wolf policy, In: Lundmark L, Sandström C (ed) Natural resources and regional development theory. Umeå: Institutionen för geografi och ekonomisk historia, universitet, Umeå, pp 98-123

Ednarsson M (2006) Attitudes towards large carnivores and carnivore tourism among tourism entrepreneurs in Sweden. Revue De Géographie Alpine 94(4):58-67

Eriksson M (2016) Rurality and collective attitude effects on wolf policy. Sustainability-Basel 8(8):711

Eriksson M (2017a) Changing attitudes to Swedish wolf policy: wolf return, rural areas, and political alienation. Ph.D. Thesis, Department of Political Science, Umeå University, Sweden

Eriksson M (2017b) Political alienation, rurality and the symbolic role of swedish wolf policy. Soc Natur Resour 30:1374-1388

Ericsson G, Bostedt G, Kindberg J (2008) Wolves as a symbol of people's willingness to pay for large carnivore conservation. Soc Natur Resour 21:294-309

Ericsson G, Heberlein TA (2003) Attitudes of hunters, locals, and the general public in Sweden now that the wolves are back. Biol Conserv 111:149-159

Eriksson M, Sandström C, Ericsson G (2015) Direct experience and attitude change towards bears and wolves. Wildlife Biol 21(3):131-137

European Commission (2005) Assessment, monitoring and reporting of conservation status - Preparing the 2001-2007. Article 17 of the Habitats Directive (DocHab-04-03/03 rev.3). European Commission, Brussels.

Frank J, Johansson M, Flykt A (2015) Public attitude towards the implementation of management actions aimed at reducing human fear of brown bears and wolves. Wildlife Biol 21(3):122-130

Glikman J, Vaske J, Bath A, Ciucci P, Boitani L (2012) Residents' support for wolf and bear conservation: the moderating influence of knowledge. Eur J Wildl Res 58:295-302
Gooden J, Moir FC (2019) Consensus, clusters, and trade-offs in wildlife-friendly ranching: an advance analysis of stakeholder goals in northern Mexico. Biol Conserv 236:443-451

Gössling S, Hultman J (eds) (2006) Ecotourism in Scandinavia. Lessons in theory and practice. Ecotourism Book Series, vol. 4, CABI Publishing

Hallgren L, Westberg L (2015) Adaptive management? Observations of knowledge coordination in the communication practice of Swedish game management. Wildlife Biol 21:165-174

Hamilton LC, Lambert JE, Lawhon LA, Salerno J (2020) Hartter J (2020) Wolves are back: sociopolitical identity and opinions on management of Canis lupus. Conserv Sci Pract 2:e213

Head BW, Alford J (2015) Wicked problems: implications for public policy and management. Admin Soc 47(6):711-739

Heberlein TA, Ericsson G (2005) Ties to the countryside: accounting for urbanites attitudes toward hunting, wolves, and wildlife. Hum Dimens Wildl 10(3):213-227

Heberlein TA, Ericsson G (2008) Public attitudes and the future of wolves (Canis lupus) in Sweden. Wildlife Biol 14:391-394

Hipela KW, Walker SB (2011) Conflict analysis in environmental management. Environmetrics 22(3):279-293

Jacobs M, Vaske J, Dubois S, Fehres P (2014) More than fear: role of emotions in acceptability of lethal control of wolves. Eur J Wildl Res 60(4):589-598

Johansson M, Karlsson J (2011) Subjective experience of fear and the cognitive interpretation of large carnivores. Hum Dimens Wildl $16: 15-29$

Jordan T (2015) Konfliktkunskap för rovdjursförvaltningen. Naturvårdsverket, Stockholm

Karlsson J, Sjöström M (2007) Human attitudes towards wolves, a matter of distance. Biol Conserv 137:610-616

Kellert S, Wilson EO (eds) (1993) The biophilia hypothesis. Island Press, Washington, DC

Kuijper DPJ, Sahle'n E, Elmhagen B, Chamaille'-Jammes S, Sand H, Lone K, Cromsigt JPGM (2016). Paws without claws? Ecological effects of large carnivores in anthropogenic landscapes. P R Soc B 283(1841)

Liberg O (2006) Genetic aspects of viability in small wolf populations - with special emphasis on the Scandinavian wolf population. Naturvårdsverket, Rapport 5436

Loorbach D, Rotmans J (2006) Managing transitions for sustainable development. In: Olsthoorn X, Wieczorek AJ (eds) Understanding Industrial Transformation, vol 44. Springer, Berlin, pp 187-206

Madden F, McQuinn B (2014) Conservation's blind spot: the case for conflict transformation in wildlife conservation. Biol Conserv 178(2014):97-106

Maji ć A, Bath A (2010) Changes in attitudes toward wolves in Croatia. Biol Conserv 143:255-260

Manfredo MJ, Dayer AA (2004) Concepts for exploring the social aspects of human-wildlife conflict in a global context. Hum Dimens Wildl 9(4):1-20

Manfredo MJ, Teel TL, Dietsch AM (2016) Implications of human value shift and persistence for biodiversity conservation. Conserv Biol 30:287-296

Manfredo MJ, Teel TL, Sullivan L, Dietsch AM (2017) Values, trust, and cultural backlash in conservation governance: the case of wildlife management in the United States. Biol Conserv 214:303-311

Mason TH, Pollard CR, Chimalakonda D, Guerrero AM, Kerr-Smith C, Milheiras S, Roberts M, Ngafack PR, Bunnefeld N (2018) Wicked conflict: using wicked problem thinking for holistic management of conservation conflict. Conserv Lett 11(6)

Matti S, Sandström A (2011) The rationale determining advocacy coalitions: Examining coordination networks and corresponding beliefs. Policy Stud J 39(3):385-410

Matti S, Sandström A (2013) The defining elements of advocacy coalitions: continuing the search for explanations to coordination and coalition structure. Rev Policy Res 30(2):240-257 
Muhly TB, Alexander M, Boyce MS, Creasey R, Hebblewhite M, Paton D, Pitt JA, Musiani M (2010) Differential risk effects of wolves on wild versus domestic prey have consequences for conservation. Oikos 119:1243-1254

Musiani M, Paquet P (2004) The practices of wolf persecution, protection, and restoration in Canada and the United States. Bioscience 54(1):50-60

Naturvårdsverket (2020) Fakta om varg - Små förändringar i vargstammen. https://www.naturvardsverket.se/Sa-mar-miljon/Vaxter-ochdjur/Rovdjur/Fakta-om-varg. Accessed 29 September 2020

Naughton-Treves L, Grossberg R, Treves A (2003) Paying for tolerance: rural citizens' attitudes toward wolf depredation and compensation. Conserv Biol 17:1500-1511

Nie M (2002) Wolf recovery and management as value-based political conflict, ethics, place and environment. J Philos Geog 5(1):65-71

Nilsson J, Sandström A, Nohrstedt D (2020) Beliefs, social identity, and the view of opponents in Swedish carnivore management policy. Policy Sci 53:453-472

Nyhus PJ, Fischer H, Madden F, Osofsky S (2003) Taking the bite out of wildlife damage: the challenges of wildlife compensation schemes. Conserv Pract 4:37-40

Persson J (1996) Vargens populationsdynamik-ett svenskt perspektiv. Report 1996:7, Dept. of Animal Ecology, Swedish University of Agricultural Sciences, Umeå

Peter C, Swilling M (2014) Linking complexity and sustainability theories: implications for modelling sustainability transitions. Sustainability-Basel 6(3):1594-1622

Peterson MN, Essen EV, Hansen HP, Peterson TR (2019) Shoot shovel and sanction yourself: self-policing as a response to wolf poaching among Swedish hunters. Ambio 48(3):230-239

Pidd M (2010) Why modelling and model use matter. J Oper Res Soc 61(1):14-24

Price M (2013) Sweden wolf cull divides wilderness opinion. http:// www.bbc.com/news/world-europe-21352209. Accessed 08 March 2017

Reed MS, Graves A, Dandy N, Posthumus H, Hubacek K, Morris J, Prell C, Quinn CH, Stringer LC (2009) Who's in and why? A typology of stakeholder analysis methods for natural resource management. J Environ Manage 90:1933-1949

Rogers H (2014) Wolf attacks on livestock, and its impact on attitudes towards wolves in Sweden. Student report No.561. Dept. of Animal Environment and Health, Swedish University of Agricultural Sciences, Sweden

Røskaft E, Bjerke T, Kaltenborn BP, Linnell JDC (2003) Patterns of self reported fear towards large carnivores among the Norwegian public. Evol Hum Behav 24:184-198

Røskaft E, Händel B, Bjerke T, Kaltenborn BP (2007) Human attitudes towards large carnivores in Norway. Wildlife Biol 13:172-185

Sand H, Liberg O, Aronson A, Forslund P, Flagstad Ö, Wabakken P, Åkesson M, Wikenros C, Karlsson J, Ahlqvist P (2014) Den Skandinaviska Vargen - en sammanställning av kunskapsläget från det skandinaviska vargforskningsprojektet SKANDULV 1998-2014. Rapport till Miljödirektoratet i Norge, Norway

Schroeder SA, Fulton DC, Cornicelli L (2018) How Minnesota wolf hunter and trapper attitudes and risk- and benefit based beliefs predict wolf management preferences. Hum Dimens Wildl 23:552-568

Sjögren-Gulve P, Hörnell-Willebrand M (2015) Favourable conservation status of the wolf in Sweden - summary of an interim report. Dept. of Research and Assessment, Brussels

Sjölander-Lindqvist A (2008) Local identity, science and politics indivisible: the Swedish wolf controversy deconstructed. J Environ Pol Plan 101:71-94

Sjölander-Lindqvist A (2009) Social-natural landscape reorganised: Swedish forest-edge farmers and wolf recovery. Conserv Soc 7:130-140
Sjölander-Lindqvist A (2011) Predators in 'agri-environmental' Sweden: rural heritage and resistance against wolf propagation. Survival and Sustainability: Environmental Concerns in the 21st century, 15-27

Sjölander-Lindqvist A, Cinque S (2014) Dynamics of participation: access, standing and influence in contested natural resource management. Partecipazione e Conflitto 7:360-383

Sjölander-Lindqvist A, Johansson M, Sandström C (2015) Individual and collective responses to large carnivore management: the roles of trust, representation, knowledge spheres, communication and leadership. Wildlife Biol 21:175-185

Skogen K, Krange O (2020) The political dimensions of illegal wolf hunting: anti-elitism, lack of trust in institutions and acceptance of illegal wolf killing among Norwegian hunters. Sociol Rural 60:551-573

Skogen K, Krange O, Figari H (2017) Wolf conflicts. Berghahn Books, New York, A sociological study

Soliku O, Schraml U (2018) Making sense of protected area conflicts and management approaches: a review of causes, contexts and conflict management strategies. Biol Conserv 222:136-145

Sponarski C, Vaske J, BATH A, Muslani M (2014) Salient values, social trust, and attitudes toward wolf management in south-western Alberta. Canada Environ Conserv 41(4):303-310

Sterman JD (2001) System dynamics modeling: tools for learning in a complex world. Calif Manage Rev 43(4):8-25

Stohr C, Coimbra E (2013) The governance of the wolf-human relationship in Europe. Rev Eur Stud 5:1-18

Treves A, Jurewicz RL, Naughton-Treves L, Wilcove DS (2009) The price of tolerance: wolf damage payments after recovery. Biodivers Conserv 18:4003-4021

Treves A, Naughton-Treves L, Shelley V (2013) Longitudinal analysis of attitudes toward wolves. Conserv Biol 27:315-323

Voinov A, Bousquet F (2010) Modelling with Stakeholders Environ Modell Softw 25(11):1268-1281

von Essen E (2016) In the gap between legality and legitimacy. Dissertation. Sveriges University of Agricultural Sciences.

von Essen E (2017) Whose discourse is it anyway? Understanding resistance through the rise of "barstool biology" in nature conservation. Environ Commun 11(4):470-489

von Essen E, Tickle L (2020) Leisure or labour: an identity crisis for modern hunting? Sociol Rural 60(1):174-197

von Essen E, Allen MP (2015) Reconsidering illegal hunting as a crime of dissent: implication for justice and deliberative uptake. Crim Law Philos 11(2):213-228

von Essen E, Hansen HP, Nordström Källström H, Peterson MN, Peterson TR (2015) The radicalisation of rural resistance: how hunting counter publics in the Nordic countries contribute to illegal hunting. J Rural Stud 39:199-209

Wiek A, Farioli F, Fukushi K, Yarime M (2012) Sustainability science: bridging the gap between science and society. Sustain Sci 7(S1):1-4

Williams CK, Ericsson G, Heberlein TA (2002) A quantitative summary of attitudes toward wolves and their reintroduction, 19722000. Wildlife Soc B 30:575-584

Wilson EO (1984) Biophilia. Harvard University Press, Cambridge

Young JK, Ma Z, Laudati A, Berger J (2015) Human-carnivore interactions: lessons learned from communities in the American West. Hum Dimens Wildl 20:349-366

Zimmermann A, McQuinn B, Macdonald DW (2020) Levels of conflict over wildlife: understanding and addressing the right problem. Conserv Sci Pract 2:e259

Publisher's Note Springer Nature remains neutral with regard to jurisdictional claims in published maps and institutional affiliations. 